\title{
PARTICIPAÇÃO POPULAR NO ÂMBITO DO PODER LEGISLATIVO DO ESTADO DE SANTA CATARINA
}

\author{
Marcos André Vieira Meller \\ Silvio Gama Farias \\ Ulisses Gabriel
}

\section{RESUMO}

Tem-se por objetivo verificar os mecanismos de participação popular no Poder Legislativo do Estado de Santa Catarina e sua relação com o Estado Democrático de Direito. Buscou-se estudar o aspecto evolutivo, começando com a democracia direta dos antigos até a chegada da novel democracia participativa ou semidireta, para, após, apresentar os casos de participação popular no Brasil, especialmente as leis de iniciativa popular, os contatos com parlamentares vias redes sociais, a manifestação popular dentro dos projetos de lei, as audiências públicas e o Parlamento Jovem dentre outros. O método é o monográfico com abordagem dedutiva e pesquisa bibliográfica e documental.

Palavras Chave: Democracia. Democracia representativa. Democracia direta e semidireta. Poder Legislativo. Santa Catarina.

\section{POPULAR PARTICIPATION AVAILABLE WITHIN THE LEGISLATIVE POWER SCOPE IN THE STATE OF SANTA CATARINA}

\begin{abstract}
The objective is to verify the mechanisms of popular participation in the Legislative Power of the State of Santa Catarina and its relationship with the Democratic State of Law. We sought to study the evolutionary aspect, starting with the direct democracy of the ancients until the arrival of the new participatory or semi-direct democracy, and then, after presenting the cases of popular participation in Brazil, especially the laws of popular initiative, contacts with parliamentarians. social networks, popular manifestation within the bills, public hearings and the Youth Parliament, among others. The method is a monograph with a deductive approach and bibliographic and documentary research.
\end{abstract}

Keywords: Democracy. Representative democracy. Direct and semi-direct democracy. Legislative power. Santa Catarina.

${ }^{1}$ Mestrandos em direito pela Universidade do Extremo Sul de Santa Catarina - Unesc.

\section{INTRODUÇÃO}

$\mathrm{Na}$ antiguidade clássica o processo de participação popular (dos efetivamente 
cidadãos) era direta, através da chamada democracia participativa. Contudo, com o advento do iluminismo e das ideias liberais, a democracia passou por uma transformação e a democracia representativa entrou em evidência. Dessa forma, um grupo de representantes eleitos passaria a dirigir os rumos da nação. Mas quando vem à tona o Estado Social ou o Estado Democrático de Direito, pós primeira guerra mundial, o povo novamente sente a necessidade de ter participação nas decisões das nações, em busca de uma democracia real, em contraposição à democracia meramente formal presente nas democracias representativas.

Diante disso, inúmeros mecanismo de participação popular acabam surgindo no mundo e, especialmente no Brasil, com o surgimento de movimentos sociais e com o advento da Constituição Federal de 1988, constatam-se o nascimento de mecanismos que alargam a participação do povo na esfera pública, como o caso do orçamento participativo e os conselhos, em especial no Poder Executivo, não podendo ser diferente âmbito do Poder Legislativo, o que de fato também ocorreu e, por consequência, a população passou a ter mais influência nas decisões atinentes à função de legislar.

Mas falando no Estado de Santa Catarina, especialmente no que concerne ao Poder Legislativo, quais foram as formas de participação popular que foram colocadas à disposição do cidadão catarinense? Essa é a resposta que pretendemos apresentar no presente estudo, sem, contudo, e é claro, esgotar a temática, face à vastidão teórica que existe em torno do Poder Legislativo, da democracia participativa e da efetiva participação popular.

No primeiro tópico do desenvolvimento deste artigo tratamos da evolução história da democracia, começando por Atenas até chegarmos ao ponto alto do chamado Estado Social, vigente a partir do fim da $1^{\text {a }}$ Guerra Mundial, falando da democracia direta na antiguidade, da democracia representativa na idade moderna e da novel democracia direta na idade contemporânea. Ato contínuo, em um segundo tópico, debatemos sobre a democracia representativa, no caso do Brasil semidireta, trazendo exemplos de casos de participação popular existente em nosso país. Por derradeiro, passamos a discutir um pouco sobre o Poder Legislativo e suas funções, o Poder Legislativo Catarinense e as formas de participação popular colocadas à disposição do povo catarinense.

O método a ser utilizado na fase de investigação foi dedutivo; já o método de procedimento será o monográfico, sendo que esse método corresponde ao estudo aprofundado de casos, desde indivíduos, grupos, comunidades e até mesmo instituições; e, a técnica de pesquisa será a bibliográfica e a documental. 


\subsection{A DEMOCRACIA E PARTICIPAÇÃO POPULAR}

Foi na Grécia, em especial no século VI, A. C. que surgiram as primeiras instituições democráticas, especialmente em Atenas, afirmando Comparato que tal sistema de governo tinha como mote as veredas que levaram ao cumprimento das leis e a participação ativa dos cidadãos (2003, p. 39).

Mas não era apenas na Grécia (pólis) que existia uma democracia em seu sentido mais amplo, com participação direta dos cidadãos, mas também podemos citar a República Romana (civitas).

Luz, ao tratar da democracia antiga, cita que:

"Poder, 'no centro' é uma imagem clara da tradição democrática antiga, da qual foram se consolidando assembleias deliberativas, ganhando força e evidência o espaço próprio para o exercício da discussão: a praça, a ágora, o coração da polis" (LUZ, 2006. p. 15).

Contudo, segundo Vieira, na idade moderna, com nasceu o Estado, "um ser abstrato e artificial, separado da sociedade e detentor do poder supremo em determinado território", sendo que a realidade liberal burguesa se fundará em uma cidadania representada, expressada pelo voto censitário, defendida por Montesquieu (2000), Locke (2005) e Sieyès (2001), apesar da defesa de Rousseau (1997) "em favor de uma vontade geral que não possa ser representada e que tem no povo, através da participação direta, a sua maior expressão" (VIEIRA, 2013, p. 37-38).

Depois dessa fase de caráter liberal estatal, vem o Estado Social de Direito, de suma importância para nossa temática, uma vez que a atuação sanitária decorre de um direito fundamental de segunda dimensão (social), presente em nossa Constituição Federal, sendo que nesse Estado se procura garantir os "denominados direitos sociais (na qualidade de ações positivas do Estado para melhorar a vida dos cidadãos) e paulatinamente irá universalizar as garantias liberais, em especial a ampliação do direito ao voto e o fim do voto censitário" (VIEIRA, 2013, p. 38).

Diante da ampla representação democrática na idade antiga, sobreveio na idade moderna o liberalismo e na idade contemporânea a social democracia, mas em que pese o mundo ter evoluído, não se alcançou evoluções efetivas na participação popular, sendo que passamos a ter uma representação política e o desaparecimento da participação direta e efetiva da cidadania (VIEIRA, 2013, p. 100). 
Para Bobbio, comparando a democracia antiga e a moderna, ele afirma que a “democracia significa o que a palavra designa literalmente: o poder do demos e não, como hoje, o poder dos representantes do demos" (BOBBIO, 2000, p. 372).

E quando se fala em demos, verifica-se em Constant o poder que o povo possuía na antiguidade, exercido de forma direta: "O povo faz as leis, examina a conduta dos magistrados, intima Péricles a prestar contas, condena generais à morte. Perdido na multidão, o indivíduo quase nunca percebe a influência que exerce”(2021, p.06), asseverando, por derradeiro que:

Concluiu-se do que acabo de expor que não podemos mais desfrutar da liberdade
dos antigos, a qual se compunha da participação ativa e constante do poder coletivo.
Nossa liberdade deve compor-se do exercício pacífico da independência privada. A
participação que, na antiguidade, cada um tinha na soberania nacional não era, como
em nossos dias, uma suposição abstrata. A vontade de cada um tinha uma influência
real; o exercício dessa vontade era um prazer forte e repetido (Constant, 2021, p.06).

Em que pese a evolução histórica, em especial no ponto envolvendo a Revolução Francesa, que ensejou o nascimento do Estado Liberal, de viés mais representativo do que participativo, conforme afirma Constant: "levados por nossa feliz revolução (eu a chamo feliz apesar de seus excessos, porque atento para seus resultados) a desfrutar os benefícios de um governo representativo" (2021, p.01), constata-se que quem o advento do Estado Social, surgiu uma necessidade maior da participação popular nos desígnios da gestão estatal.

Para Constant:

O perigo da liberdade antiga estava em que, atentos unicamente à necessidade de garantir a participação no poder social, os homens não se preocupassem com os direitos e garantias individuais. $\mathrm{O}$ perigo da liberdade moderna está em que, absorvidos pelo gozo da independência privada e na busca de interesses particulares, renunciemos demasiado facilmente a nosso direito de participar do poder político (2021).

Democracia representativa, entende-se neste caso por "representar" o ato de uma pessoa ser eleita, por votação, para "representar" um povo, uma população, determinado grupo, comunidade etc., normalmente esta pessoa representa um grupo (partido, cidade, bairro), também podemos eleger comissões e associações para nos representar, isto é, para agir, falar e decidir em "nome do povo", em nome de uma comunidade, de um grupo. Os "representantes do povo" se agrupam em instituições chamadas Parlamento, Câmaras, Congresso ou Assembleia da República.

Segundo Vieira:

Outro aspecto a ser ressaltado é que o liberalismo, na vertente po- lítica, trouxe ao palco a democracia como forma de governo, exercida dentro do Estado Liberal. Não mais a democracia dos antigos, direta e participativa, mas uma democracia, 
representativa e censitária, de acor- do com os interesses da burguesia, considerando os indivíduos isolada- mente como os titulares dos direitos políticos e não aceitando a existên- cia de nenhum grupo intermediário na relação indivíduos e Estado (2012, p. 124).

Montesquieu observa que a grande maioria dos cidadãos não têm capacidade de governar, cabendo a eles, então, escolher os que possuem tal condição. No mesmo sentido, afirma que o povo não pode ser seu próprio governante. Para ele, não há possibilidade do povo participar diretamente da gestão pública, devendo escolher os representantes para tanto, já que "povo não é, de modo algum, capaz disso, fato que constitui um dos graves inconvenientes da democracia” (MONTESQUIEU, 2000, p. 47). “Ele só deve participar do governo para escolher seus representantes, procedimento para o qual é bastante capaz" MONTESQUIEU, 2000, p. 205).

Mas como assevera Vieira, o mundo passou por grande transformação com o surgimento do Estado Social e a nova roupagem dada ao termo cidadania, que passa a ter um caráter necessariamente participativo, tendo bases dentro do Estado Social Democrático ou Democrático de Direito, a qual deve "deve ser construída dentro de uma leitura pós-moderna, que possibilite o resgate do elemento participativo, político e jurídico da Sociedade e constitua espaços de ágora públicos coletivos ou públicos não-estatais" (VIEIRA, 2012, p. 153)

Ora, o regime da democracia participativa é um regime onde se pretende que existam efetivos mecanismos de controle da sociedade civil sob a administração pública, não se reduzindo o papel democrático apenas ao voto, mas também estendendo a democracia para a esfera social.

Segundo Bonavides, "não há teoria de democracia participativa que não seja, ao mesmo passo, uma teoria material da constituição", sendo necessário um controle que deve combinar a "a autoridade e a judicatura dos tribunais constitucionais" e a "a autoridade da cidadania popular e soberana exercitada nos termos decisórios de derradeira instância" (2001, p. 25).

Para Costa, "a 'democracia participativa' pretende ser uma tentativa de reação às promessas não mantidas da democracia representativa", concedendo aos cidadãos o poder de iniciativa política e de influência no processo de decisão, em busca de uma democracia real, já que a iniciativa política e a influência no processo de decisão da sociedade acabaram comprometidos pelo formalismo do sistema representativo e pelo elitismo existente nos partidos políticos, que restringem a participação popular (2012, p. 300). 
Na visão de Costa, “a democracia 'real' (contraposta ao formalismo da democracia representativa) deve coincidir com a reapropriação do poder de falar e de decidir por parte dos sujeitos concretamente operantes na sociedade: nas empresas, na escola, na administração pública, nas mais diversas instituições" (2012, p. 300).

Para Vieira, citando Montesquieu e Locke, "a democracia direta era algo que não seria possível de ser colocada em prática” (2012, p.124), dada sua complexidade. Sendo que Vieira, citando Cerroni (1982) afirma que, para o pensamento liberal iluminista, apenas a elite teria condições para soluções políticas (2012, p. 121).

Em nossa Constituição atual, de 1988, verifica-se de forma clara que vivemos sob a égide de um Estado Democrático de Direito, que tem como fundamentos a soberania, a cidadania, a dignidade da pessoa humana, os valores sociais do trabalho e da livre iniciativa e o pluralismo jurídico (artigo 1o e seus incisos), dando status constitucional não apenas à democracia representativa, mas a participativa, quando afirma no parágrafo único do artigo citado que: "todo o poder emana do povo, que o exerce por meio de representantes eleitos ou diretamente, nos termos desta Constituição."

Pela leitura do parágrafo citado, constata-se a existência de elementos de democracia representativa e de democracia direta, surgindo o termo democracia semidireta. Para Vieira (2012, p. 178):

\begin{abstract}
"Esta modalidade de exercício da cidadania restou instituída no artigo 14, incisos I a III da CRFB/1988 e regulamentada pela Lei 9.709/98. Ela se traduz no referendo, o plebiscito e na iniciativa popular, que podem ser utilizados no Brasil, em todas as unidades federativas. $\mathrm{O}$ referendo é uma consulta ao povo sobre uma alteração legislativa, constitucional ou não. O legislativo aprova a proposição, mas esta somente terá aplicação após ser referendada pelo povo em consulta popular. Deste modo, o povo adquire o poder de sancionar as leis. No plebiscito, consulta-se o povo antes da elaboração da lei, o que a posteriori pode levar a sua confecção. Já a iniciativa popular é um mecanismo que possibilita a certo número de eleitores (conforme previsto na Constituição ou na legislação infraconstitucional) de efetuar junto ao parlamento a proposição de uma emenda constitucional ou projeto de lei, funcionando como o iniciador do processo legislativo (BENEVIDES, 2000; DALLARI, 2009; SILVA, 2011; SGARBI, 1999; CAETANO, 2003; BONAVIDES, 1996, p. 282).
\end{abstract}

Além disso, segundo Vieira (2012, p. 178):

"Além das três espécies insertas na CRFB/1988, podem ser destacadas (que não são aplicadas no Brasil): a) o recall: utilizado tanto para a revogação de um mandato (a partir de um requerimento de certo número de eleitores, possibilitando, àquele que se pretende revogar o mandato, o direito de defesa), como para a revogação de uma decisão judicial (utilizada em alguns estados-membros dos EUA, permite a revogação de decisão de um juiz ou tribunal, quando reconhecer a inconstitucionalidade de uma lei. Não se aplica às decisões da Suprema Corte); b) o veto popular: permite aos eleitores certo prazo, para, querendo, requererem ou não a suspensão do resultado da aprovação de uma lei, até que seja posta em consulta 
popular; c) iniciativa popular direta: é uma modalidade de iniciativa popular, cujo projeto que preenche os requisitos legais deve ser colocado para aprovação dos eleitores na próxima eleição; d) iniciativa popular indireta: também se caracteriza como uma espécie de iniciativa popular, na qual o projeto que preenche os requisitos legais é discutido e votado pelo Legislativo, e, caso venha a ser rejeitado, será submetido à apreciação dos eleitores na próxima eleição (DALLARI, 2009; BONAVIDES, 2006).

Segundo Cabral, com o advento da Constituição de 1988, a possibilidade de participação dos cidadãos no processo político tiveram vasta ampliação, conforme já conseguimos observar acima. "Assim, no âmbito das mudanças implementadas com o processo de redemocratização do Estado brasileiro tem sido observado o alargamento da cidadania e o crescimento da democracia na esfera local" (CABRAL, 2021, p. 1).

Para a autora:

\begin{abstract}
"Segundo Dallari, a preocupação com a ideia de justiça é muito antiga, contudo, para que se possa realizar a justiça social é necessário possibilitar a todos os seres humanos as mesmas chances de participar da vida social, incluindo-se a participação no uso da liberdade e das riquezas, no uso dos serviços e no recebimento de proteção, assim como participação no governo. É nesse sentido que se deve entender a importância da participação popular para o aperfeiçoamento da democracia, haja vista que a participação da população nas decisões políticas permite o aprofundamento do debate democrático e a construção de novas formas de relacionamento entre o Estado e os administrados" (CABRAL, 2021, p. 16).
\end{abstract}

Fazendo uma leitura da CRFB/1988 percebe-se que há pelo menos 30 artigos que tratam direta ou indiretamente da participação popular no âmbito da gestão pública, começando pelos princípios que visam consolidar a democracia (artigos 1o , 5o , 8o , 15 e 17), passando pelos deveres sociais em questões coletivas (Artigos 205, 216, 225, 227 e 230) e o exercício da soberania popular (Artigos 14, 27, 29, 58 e 61), mas também tratou da participação social como forma de gestão pública (Artigos 10, 18, 37, 74, 173, 187 e 231). (TEIXEIRA et al., 2012, p, 10).

\title{
2.2 OS PROCESSOS NACIONAIS DE PARTICIPAÇÃO POPULAR
}

Segundo Ribeiro e Rosa, "a redemocratização do Brasil nos anos oitenta do século passado estimulou o surgimento de inúmeros conselhos participativos e deliberativos em diversos setores e níveis da administração pública", sendo que eles permitiram verificar avanços e problemas no desenvolvimento da participação popular, face a manifesta crise da chamada democracia representativa $(2018$, p. i) 
Sobre a participação popular no Brasil, Ciconello afirma que o povo brasileiro, além do voto, "têm ao seu alcance uma pluralidade de instâncias e de mecanismos de alargamento da esfera pública, normatizados e inseridos dentro da burocracia estatal, por pressão de organizações da sociedade civil” (2021, p. 1), sendo que no Brasil, durante a ditadura militar, surgiram milhares de organizações "- formais e informais -, militantes, religiosos, intelectuais e movimentos sociais inspirados, principalmente, por referenciais teóricos e morais, como a Teologia da Libertação e o movimento pedagógico criado pelo brasileiro Paulo Freire, chamado Educação Popular" (CICONELLO, 2021, p. 2).

Para o autor, foi nos anos 70 e 80 que surgiram as primeiras organizações embrionárias, no Brasil, que visavam a participação social no processo de construção da sociedade, já que no período foram fechados sindicatos, partidos e universidades, sendo essas organizações, pautadas na luta pelos direitos humanos e pela constituição de novos direitos, instrumentos que buscavam, de forma inédita a ação política e de sociabilidade, construindo uma nova dimensão ou segmento, que foram as associações de moradores e bairros (Ciconello, 2021, p. 3).

Com a gradual abertura política, criou-se o Partido dos Trabalhadores (PT) e a Central Única dos Trabalhadores (CUT), os quais promoveram, em especial o PT, no início de sua caminhada, experiências participativas como o "orçamento participativo" na cidade de Porto Alegre, onde de debatia e deliberava sobre o destino de parte do orçamento público seria empregado (CICONELLO, 2021, p. 3).

Segundo Costa.

O ponto de partida dos fenômenos que hoje podemos associar ao esquema da 'democracia participativa' é uma experiência, iniciada no Brasil, na cidade de Porto Alegre, em 1989 (...) naquele momento no governo da cidade (PT), com o objetivo de envolver os cidadãos no complexo processo de aprovação da lei do orçamento municipal (2012, p. 301/302).

Mas não foi apenas essa a espécie de participação social que surgiu, salientando Ciconello que:

Ao longo dos últimos 20 anos, foram construídos diferentes espaços formais de participação nos âmbitos federal, estadual e municipal. Assim, por exemplo, estimase que existam, atualmente, mais de 40.000 Conselhos de Políticas Públicas, ligados a diversas estruturas governamentais e que contam com a participação de milhares de organizações da sociedade civil em todo o país. Apresentar essa inovação institucional, seus impactos e desafios para a consolidação e ampliação da democracia é o que se pretende realizar (2021, p. 1).

Para Teixeira et al.,

O texto constitucional de 1988 indicou princípios e diretrizes para a atual arquitetura da participação, tendo apontado a inclusão de cidadãs e cidadãos no processo 
decisório como maneira de efetivar a gestão pública participativa. Foram justamente esses preceitos legais que deram espaço para a institucionalização de conselhos e para a realização de conferências. No entanto, a operacionalização dessas garantias depende das estruturas institucionais desenhadas a partir de visões sobre a sociedade civil e a finalidade de sua participação na formulação de políticas públicas (2012, p. 40).

Todavia, conforme Costa, "estamos muito longe - como é evidente - das experiências de democracia participativa. (...) mas é necessário 'mostrar a possibilidade e a oportunidade de combinar o governo dos 'poucos' com as iniciativas e a participação de 'muitos"” (2012, p. 307). Para Avritzer, "portanto, o primeiro pilar de uma concepção moral de democracia consiste na ideia a política enquanto autodeterminação de uma comunidade de iguais capazes de discutir as regras de sua organização", (2012, p. 154) ou seja, sem cidadania efetiva, não existe democracia, ainda que sejam grupos minoritários, pois para o pluralismo jurídico, é necessária a existência de espaços para "legitimação de novas práticas normativas, na medida em que possibilitam a participação no processo decisório de grupos minoritários e novos atores sociais, a fim de trazerem à tona seus interesses " (WOLKMER, 2017, p. 12).

Assim, além das nossas liberdades individuais e do direito à democracia representativa, temos que ter direito à uma democracia participativa. Para Costa:

A expressão 'democracia participativa' - um lema que está sofrendo, nas últimas décadas, uma crescente difusão - parece redundante: a democracia per se evoca a exigência de envolver o maior número possível de sujeitos (tendencialmente 'todos' os sujeitos) na gestão da coisa pública (2012, p. 299).

Na visão de Santos, o aumento da participação social nos países recém democratizados do Sul foi exitosa porque os atores sociais conseguiram transferir práticas e informações do nível social para o nível administrativo, sendo que.

Inovações institucionais que parecem bem-sucedidas nos países do Sul estão relacionadas ao que Castoríadis denomina de instauração de um novo eidos, isto é, de uma nova determinação política baseada na criatividade dos atores sociais (2002, p. 54).

Santos afirma que.

Os processos recentes de democratização também incorporaram esse elemento de instituição da participação. No caso do Brasil, durante o processo de redemocratização movimentos comunitários reivindicaram em diversas regiões do pais, em particular na cidade de Porto Alegre, o direito de participar nas decisões em nível local (2020, p. 58).

Com esse processo, surgiu uma inovação sem precedentes, decorrente da participação de atores sociais na tomada de decisões, o que passou a incluir temáticas muitas vezes ignoradas pelo meio político, aumentando a participação principalmente em nível local 
(SANTOS, 2002, p. 59). Não existindo, na visão de Bonavides, "uma democracia sem povo" (2001, p. 48).

\title{
2.3 AS FORMAS DE PARTICIPAÇÃO POPULAR NO ÂMBITO DO PODER LEGISLATIVO DE SANTA CATARINA
}

$\mathrm{Na}$ forma do artigo 45 da Constituição Federal.

\begin{abstract}
A Câmara dos Deputados compõe-se de representantes do povo, eleitos, pelo sistema proporcional, em cada Estado, em cada Território e no Distrito Federal. § $1^{\circ}$ O número total de Deputados, bem como a representação por Estado e pelo Distrito Federal, será estabelecido por lei complementar, proporcionalmente à população, procedendo-se aos ajustes necessários, no ano anterior às eleições, para que nenhuma daquelas unidades da Federação tenha menos de oito ou mais de setenta Deputados[...].
\end{abstract}

Segundo o TSE, o número de Deputados Federais é proporcional à população de cada Estado, Santa Catarina tem 16 Deputados Federais, em decisão proferida no ano de 2013. (https://www.tse.jus.br/imprensa/noticias-tse/2013/Abril/tse-redefine-cadeiras-na-camara-dosdeputados-para-eleicoes-2014)

Conforme o artigo 27 da Constituição Federal,

O número de Deputados à Assembléia Legislativa corresponderá ao triplo da representação do Estado na Câmara dos Deputados e, atingido o número de trinta e seis, será acrescido de tantos quantos forem os Deputados Federais acima de doze.

Diante dessas regras, Santa Catarina possui 40 Deputados Estaduais que que compõe o poder legislativo. De acordo com o artigo 33 da Constituição do Estado de Santa Catarina.

O Poder Legislativo é exercido pela Assembleia Legislativa, constituída de Deputados, representantes do povo, eleitos pelo voto direto e secreto, em sistema proporcional, dentre brasileiros maiores de vinte e um anos, atendidas as demais condições da legislação eleitoral.

Santa Catarina é um dos 27 Estados da federação, possui uma área de 95733 km² e segundo o Censo de 2010 tem 6.248.436 habitantes, sendo que a expectativa é de 7.001.161 em 2017, estando a Assembleia Legislativa situada na Capital do Estado de Santa Catarina, Florianópolis, Florianópolis, remontando seu "nascimento" a 12 de agosto de 1834, conforme o contido em seu sítio eletrônico na internet. (http://www.alesc.sc.gov.br/sobre)

Como verificamos, temos no Brasil, na verdade, uma democracia semidireta, tanto em nível federal como em nível estadual. Em nível estadual, as assembleias legislativas representam o poder legislativo, fiscalizando e legislando. 
Segundo Moraes.

A Constituição Federal consagrou em seu artigo 2 a tradicional tripartição de Poderes, ao afirmar que são Poderes do Estado, independentes e harmônicos entre si, o Legislativo, o Executivo e o Judiciário", sendo que as "funções típicas do Poder Legislativo são legislar e fiscalizar, tendo ambas o mesmo grau de importância (2006, p. 379) .

Châtelet et al., afirmam que Locke, ao tratar do direito natural aduz que cabe ao poder público realizá-lo, sendo esse poder soberano, "no sentido dos que os instituíram, e na medida em que ele atue, segundo seu fim, são obrigados a obedecer-lhe e a lhe prestar apoio. Três são suas tarefas: legislador [...] juiz [...] e governante [...]" (1990, p. 59).

E na continuidade da obra, os autores asseveram que legislador.

Fixa regras de exercício da soberania - e as leis orgânicas do Estado ou sua Constituição - e define as leis que formam o direito público e o direito privado, tendo como perspectiva aplicar os direitos da natureza às particularidades empíricas da sociedade(1990, p. 59).

Diante disso verifica-se que a democracia participativa não caberá apenas ao Poder Executivo, mas, o Poder Legislativo, apresentar mecanismos para efetiva participação popular, além da previsão constitucional do artigo 50 que trata da iniciativa de leis, que pode ser através do povo, com subscrição do projeto por no mínimo um por cento dos eleitores do Estado, distribuídos em pelo menos 20 municípios com não menos de um por cento dos eleitores de cada um deles (artigo 50 da Constituição do Estado de Santa Catarina).

Em se tratando da participação popular no processo legislativo na esfera estadual Catarinense, nota-se uma evolução gradativa, com demonstração expressiva de influência do cidadão nos temas de maior relevância discutidos no parlamento. A principal forma de participação popular no processo legislativo continua sendo a interação do eleitor com o parlamentar, que varia de acordo com a característica da atuação de cada deputado, seja através do contato interpessoal, na representação da sua entidade de classe, ou, ainda, dos seus representantes municipais. O e-mail ainda é o mecanismo digital mais utilizado pelo cidadão para representar suas demandas. Outro mecanismo de participação popular por meio digital que vem ganhando notoriedade é a chamada "Manifestação Popular", onde é permitido ao cidadão, desde que cadastrado no sistema de Processo Legislativo da ALESC, manifestar sua opinião "favorável”, ou "contrária" a proposição em análise, conforme o quadro 01 abaixo: 


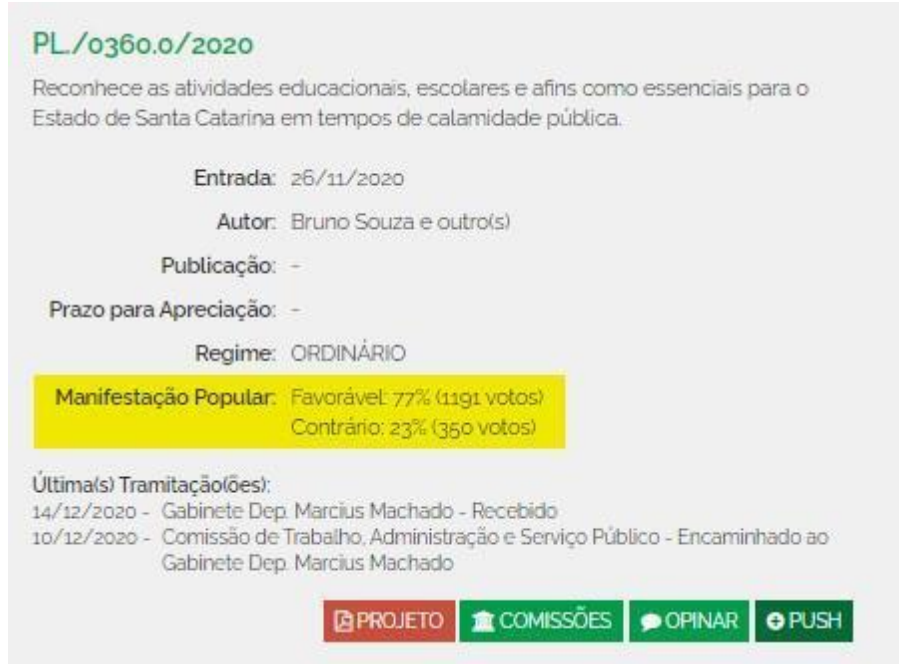

Fonte: ALESC(2020).

Grande parte da participação popular na ALESC continua sendo realizada de forma convencional, através de Audiência Pública e suspensões das sessões ordinárias para manifestação de entidades com objetivo de tratar assuntos de relevante interesse público. A Audiência Pública é a reunião requerida por Comissão Permanente da ALESC, com a participação de entidades da sociedade civil, movimentos sociais organizados e com órgãos públicos constituídos para tratar de matérias em tramite ou de relevante interesse público, garantida a divergência das correntes de opinião.

Segundo o artigo $8^{\circ}$ do Regimento Interno da Assembleia Legislativa de Santa Catarina, a "Audiência pública é a reunião de Comissão Permanente ou Comissões Permanentes da Assembleia Legislativa com entidades da sociedade civil, movimentos sociais organizados e com órgãos públicos constituídos de todas as esferas de Poder para instruir matéria legislativa em trâmite ou para tratar de assunto de interesse público."

Por fim, também configura a participação popular no processo legislativo - as sessões especiais destinada a homenagens específicas e de interesse público, e o Parlamento Jovem. O Parlamento Jovem traz à ALESC 40 (quarenta) estudantes do ensino médio de escolas de oito regiões do Estado. ${ }^{2}$

Durante uma semana, os estudantes vivenciam a rotina dos deputados, com a participação em reuniões das comissões e na sessão ordinária. O programa tem

\footnotetext{
${ }^{2}$ (http://agenciaal.alesc.sc.gov.br/index.php/noticia_single/dez-projetos-de-leis-saeo-aprovados-nasessaeo-do-parlamento-jovem)
} 
reconhecimento nacional e originou diversas leis atualmente em vigor em Santa Catarina, tais como; A Semana de Combate ao Bullying de Santa Catarina. ${ }^{3}$

As suspensões de sessão, com finalidade de manifestação popular não são instrumentos regimentais formais, e originam-se de acordo dos membros. Na maior parte das vezes, o espaço é utilizado por representações municipais com intuito de destacar as festividades e demais atrações do município representado, bem como, por vezes, também, a tribuna é utilizada por representantes de entidades de classe para manifestar opinião sobre determinado assunto.

\section{CONCLUSÃO}

O presente estudo teve por objetivo estudar as formas de participação popular disponibilizadas pela Assembleia Legislativa de Santa Catarina em benefício do cidadão catarinense. Para tanto, realizamos um estudo bibliográfico sobre temáticas que sustentam a chamada democracia participativa, especialmente a evolução história da democracia e a participação popular, os casos nacionais de democracia direta ou, no caso do Brasil, semidireta, até efetuarmos uma pesquisa bibliográfica e documental acerca dos instrumentos que o poder legislativo de Santa Catarina dispõe ao povo.

No primeiro tópico do estudo, constatamos que a democracia surge na Grécia, em Atenas, com as primeiras instituições democráticas atenienses, onde havia efetiva participação político-social dos cidadãos gregos, não sendo apenas na Grécia, com a pólis que existia tal participação direta, mas também em Roma, com a civitas. A democracia foi se moldando ao longo dos tempos atingindo, com o iluminismo e as ideias liberais a chamada democracia representativa, onde representantes eleitos pelo povo, seriam capazes e só eles, de dirigir a nação.

Contudo, com o advento da $1^{\text {a }}$ Guerra Mundial e a necessidade de mudanças de paradigmas para atender as demandas sociais, veio à baila uma pressão para que o povo pudesse, diretamente, participar da condução da nação em determinados pontos, mesmo que o retorno da democracia direita antiga fosse inviável. Aí, então, começaram a surgir mecanismos de participação popular na gestão administrativa pública, em especial no Brasil com a Constituição Federal de 1988, chamada democracia semidireta, citando, de forma

\footnotetext{
3 (https://www.sintonia.fm.br/noticias/alto-vale/geral/projeto-sugerido-por-alunos-de-ituporanga-eapresentado-pelo-deputado-milton-hobus-cria-a-semana-de-combate-ao-bullying-de-sc-30285.html)
} 
sintética, como exemplos o plebiscito, o referendo, a lei de iniciativa popular, bem como pelo menos 30 artigos que indicam a participação popular em nível constitucional.

No tópico seguinte analisamos casos de participação popular direta que nasceram no Brasil a partir de embriões que nasceram na década de 70 e 80, decorrentes especialmente de associações de moradores e bairros, bem como de sindicatos, partidos e faculdades remanescentes do período ditatorial, além da CUT e do PT, que foi o partido responsável por uns dos casos de sucesso de participação popular no Brasil, que foi o orçamento participativa na cidade de Porto Alegre, não podendo deixar de citar, também os diversos conselhos de políticas públicas surgidos pós-redemocratização, em torno de mais de 40.000 nos três âmbitos da federação.

Por fim, buscou-se as formas de participação popular no âmbito Poder Legislativo do Estado de Santa Catarina, onde há além da possibilidade de leis de iniciativa popular, contatos com parlamentares vias redes sociais, em especial o e-mail, a manifestação popular dentro dos projetos de lei, as manifestações populares dentro da sessões, as audiências públicas, dentre as quais do orçamento, e o Parlamento Jovem, o que implica em considerar que, cada vez mais, o parlamento, ainda de forma incipiente, visa a mais participação popular em suas funções típicas, de fiscalizar e legislar.

\section{REFERÊNCIAS}

ALBUQUERQUE, J. A. Guilhon. Montesquieu: sociedade e poder. In: WEFFORT, Francisco C. Os clássicos da política: Maquiavel, Hobbes, Locke, Montesquieu, Rousseau, "O Federalista", v. 1. 13. ed. São Paulo: Ática, 2000. p. 111-120.

AMABILE, Antônio Eduardo de Noronha. Administração Pública. Dicionário de Políticas Públicas (CASTRO, Carmem Lúcia Freitas de. et al - organizadores). Barbacena: Eduemg, 2012)

ANDRADE, Bonifácio José Tamm de Andrada. Federação. Dicionário de Políticas Públicas (CASTRO, Carmem Lúcia Freitas de. et al - organizadores). Barbacena: Eduemg, 2012)

AVRITZER, Leonardo. Teoria crítica e teoria democrática. Do diagnóstico da impossibilidade da democracia ao conceito de esfera pública. In: Novos Estudos. São Paulo: CEBRAP, 1999, nº 53. p.167-188.

AVRITZER, Leonardo. A moralidade da democracia. São Paulo: Perspectiva, 2012. 
BOBBIO, Norberto. Teoria geral da política: a filosofia política e as lições dos clássicos. Organizado por Michelangelo Bovero. Tradução de Daniela Beccaccia Versiani. 20. reimp. Rio de Janeiro: Elsevier, 2000.

BENEVIDES, Maria Victoria de Mesquita. A cidadania ativa: referendo, plebiscito e iniciativa popular. São Paulo: Editora Ática, 1991. BOBBIO, Norberto. Teoria Geral da Política. (Tradução Daniela Beccaccia Versiani) Rio de Janeiro: Campus, 2000.

Teoria Geral da Política: a filosofia política e as lições dos clássicos.

(Organizado por Michelangelo Bovero e traduzido por Daniela Beccaccia Versiani). Rio de Janeiro: 2000. $9^{\mathrm{a}}$ reimpressão.

BONAVIDES, Paulo. Teoria constitucional da democracia participativa: por um direito constitucional de luta e resistência, por uma nova hermenêutica, por uma repolitização da legitimidade. 1. ed. São Paulo: Malheiros, 2001.

BONAVIDES, Paulo. Curso de Direito Constitucional. 15 ed. São Paulo: Malheiros, 2004. Disponível: https://papers.ssrn.com/sol3/papers.cfm?abstract_id=3329942

BOURDIEU, Pierre. Razões práticas: sobre a teoria da ação. Papirus Editora, 1996.

BOURDIEU, Pierre. Sobre o Estado. Companhia das Letras. São Paulo. 2014.

BOURDIEU, Pierre. "O campo político." Revista Brasileira de Ciência Política 5 (2011): 193-216.

BRASIL. Constituição (1988). Constituição da República Federativa do Brasil. Diário Oficial [da] União, Poder Legislativo, 15 de Nov. 1988.

BUCCI, Maria Paula Dallari. Método e aplicações da abordagem direito e políticas públicas (DPP). Rev. De Estudos Institucionais, v. 5, n. 3, p. 791-832, set./dez. 2019. Rio de Janeiro. Disponível em: https://estudosinstitucionais.com/REI/article/view/430/447

CABRAL, Lucíola Maria de Aquino. Controle social e democracia participativa. Disponível em:

file:///Users/UlissesGabriel/Downloads/CONTROLE SOCIAL E DEMOCRACIA PARTI CIPATI.pdf. Acesso em 21 de fev. de 2021.

CAMARGO Aranha Filho, Adalberto José Queiroz Telles de. Crimes na Internet e a legislação vigente". Revista Literária de Direito, n o 44, p. 23, outubro-dezembro/2002.

CANOTILHO, José Joaquim Gomes. Direito constitucional e teoria da Constituição. 6. ed. Coimbra: Almedina, 2002. 
CANOTILHO, José Joaquim Gomes; MOREIRA, Vital. Os Poderes do Presidente da República (especialmente em matéria da defesa de política externa). Coimbra: Coimbra Ed., 1991.

CAPELlA, Ana Cláudia. Perspectivas teóricas sobre o processo de formulação de políticas públicas. In: Hochman, Gilberto; Arretche, Marta; Marques, Eduardo (Orgs.). Políticas públicas no Brasil. Rio de Janeiro: Editora Fiocruz, 2008. p. 87-124.

CHÂTELET, François; DUHAMEL, Olivier; PISIER-KOUCHNER, Evelyne. História das idéias políticas. Tradução de Carlos Nelson Coutinho. 2. Ed. Rio de Janeiro: Jorge Zahar, 1990.

CHUEIRI, Vera Karam de. O discurso do constitucionalismo: O governo das leis versus governo do povo. In: Direito e Discurso: discursos do direito. (Organização de Ricardo Marcelo Fonseca). Florianópolis: Fundação Boiteaux, 2006. CITTADINO, Gisele. Pluralismo, Direito e Justiça Distributiva. 4. ed. Rio de Janeiro: Lúmen Júris, 2009.

CICONELLO, Alexandre. A Participação Social como processo de consolidação da democracia no Brasil. Disponível em: http://cebes.org.br/site/wpcontent/uploads/2014/03/AParticipacao-Social-como-processo-de-consolidacao-dademocracia-no-Brasil.pdf. Acessado em: 21 de fev. de 2021. (Este estudo de caso foi escrito como contribuição ao livro From Poverty to Power: How Active Citizens and Effective States Can Change the World, Oxfam International 2008).

COELHO, Saulo de Oliveira Pinto; ASSIS, Alline Neves de. Um constitucionalismo de espetáculo. Rev. Brasileira de Estudos Políticos, n. 115, p. 541-584, jul./dez. 2017. Belo Horizonte.

COMPARATO, Fábio Konder. Fundamentos de Direitos Humanos. Disponível em: http://www.iea.usp.br/publicacoes/textos/comparatodireitoshumanos.pdf.

COMPARATO, Fábio Konder. A afirmação histórica dos direitos humanos. 3. ed., rev. e ampl. São Paulo: Saraiva, 2003.

COMPARATO, Fábio Konder. Ciência Política. 10 ed. São Paulo: Malheiros, 2000.

COMPARATO, Fábio Konder. Do Estado Liberal ao Estado Social. 7. Ed. São Paulo: Malheiros, 2007.

CONSTANT, Benjamin. Da liberdade dos antigos comparada a dos modernos. Disponível em https://www.fafich.ufmg.br/ luarnaut/Constant liberdade.pdf. Acesso em 21 de fev. de 2021.

CRUZ, Paulo Márcio. Fundamentos do Direito Constitucional. 2 ed. Curitiba: Juruá, 2003.

COSTA, Pietro. Poucos, muitos e todos: lições de história da democracia. Traduzido por Luiz Ernani Fritoli. Curitiba: Editora UFPR, 2012. 
DALLARI, Dalmo de Abreu. Elementos da teoria geral do Estado. 11. Ed. São Paulo: Saraiva, 1985.

DALLARI, Sueli Gandolfi. O direito à saúde. Rev. Saúde Pública, São Paulo, v. 22, n. 1, p. 57-63, 1988a.

DECLARAÇÃO DOS DIREITOS DO HOMEM E DO CIDADÃO, votada em 02 de outubro de 1789. In: DHnet. Disponível em: <http://www.dhnet.org.br/direitos/anthist/dec1789.htm>. Acesso em: 24 jan. 2013.

DUDH. Declaração Universal dos Direitos Humanos. Adotada e proclamada pela Resolução 217A (III) da Assembleia Geral das Nações Unidas em 10 de dezembro de 1948. Disponível em: <http://portal.mj. gov.br/sedh/ct/legis_intern/ddh_bib_inter_universal.htm>. Acesso em: 20 fev. 2013.

EASTON, David. Uma teoria de análise política. Rio de Janeiro: Zahar, 1968.

ETZIONI, Amitai. La dimensión moral: hacia una nueva economía. Madrid: Palabra, 2007.

ETZIONI, Amitai. La nueva regla de oro: comunidad y moralidad en una sociedad democrática. Barcelona: Paidós Iberica, 1999.

ETZIONI, Amitai. Reexame da estratégia mista de decisão. In: HEIDEMANN, F.G.; SALM, J.F. (org.) Políticas públicas e desenvolvimento: bases epistemológicas e modelos de análise. Brasília: Edunb, 2009, p. 233-237.

FARAH, Marta Ferreira Santos. Administração pública e políticas públicas. Rev. Adm. Pública, v. 45, n. 3, p. 813-836, 2011.

.Análise de políticas públicas no Brasil: de uma rática não nomeada à institucionalização do "campo de públicas". Revista de Administração Pública, v. 50, n. 6, p. 959-979, 2016.

Formação em política pública no Brasil. Das iniciativas pioneiras dos anos 60 à institucionalização do "campo de públicas". Estudos políticos , v. 49, p. 192-215, $2016 b$.

FARAH, Marta Ferreira Santos et al., Gênero e política pública: panorama da produção acadêmica no Brasil (1983-2015). Cadernos Ebape, v. 16, n. 3, p. 428-443, jul./set. 2018.

FARIA, Carlos Aurélio Pimenta de. Ideias, conhecimento e políticas públicas: um inventário sucinto das principais vertentes analíticas recentes. Revista Brasileira de Ciências Sociais, v. 18, n. 51, p. 21-29, 2003.

FARIA, Carlos Aurélio Pimenta de. Implementação: ainda o "elo perdido" da análise de políticas públicas no Brasil? In: Faria, Carlos Aurélio Pimenta de. Implementação de políticas públicas: teoria e prática. Belo Horizonte: Ed. PUC Minas, 2012a. p. 123-153. 
FUKS, Mario. Definição da agenda, debate público e problemas sociais: uma perspectiva argumentativa da dinâmica do conflito social. In: Bib, n.49, p. 79-94, 2000.

GIL, Antônio Carlos. Métodos e técnicas de pesquisa social. São Paulo: Atlas, 2008.

GOYARD-FABRE, Simone. O que é Democracia? (Tradução Cláudia Berliner) São Paulo: Marins Fontes, 2003.

HABERMAS, Jürgen. Direito e Democracia: entre facticidade e validade. (Tradução Flávio Beno Siebeneichler) 2.ed. Rio de Janeiro: Tempo Brasileiro, 2003, v. I.

.Direito e Democracia: entre facticidade e validade. (Tradução Flávio Beno Siebeneichler) 2.ed. Rio de Janeiro: Tempo Brasileiro, 2003, v. II.

A inclusão do outro - estudos de teoria política. (Tradução George Sperber e Paulo Astor Soethe) São Paulo: Edições Loyola, 2000.

A Soberania Popular como forma de procedimento. (Tradução de Márcio Suzuki). In: Novos Estudos, CEBRAP, nº 26, março de 1990.

HAMILTON, Alexander; MADISON, James; JAY, John. O federalista. Tradução de Hiltomar Martins Oliveira. Belo Horizonte: Líder, 2003.

1984.

.O federalista. Tradução de Heitor Almeida Herrera. Brasília: UnB,

HOBBES, Thomas. Leviatã. Matéria, forma e poder de um Estado eclesiástico e civil. (Tradução de João Paulo Monteiro e Maria Beatriz Nizza da Silva). 3. ed. São Paulo: AbrilCultural, 1983. Col. Os Pensadores.

. Leviatã. (Tradução de João Paulo Monteiro, Maria Beatriz Nizza da Silva

e Cláudia Berliner.) 1. ed. São Paulo: Martins Fontes, 2003.

IANNI, Octávio. A questão social. Revista USP, set., out. e nov. São Paulo, p. 145 a 154).

IBGE. Censo Demográfico, 2010. Disponível em: <www.ibge.gov.br〉. Acesso em 21 de fev. de 2021.

LAFER apud GONET BRANCO, In: MENDES, G. F. (org.). Hermenêutica constitucional e direitos fundamentais. Brasília: Brasília Jurídica, 2000.

LUZ, Vladimir de Carvalho. Democracia dos pós-modernos? Notas sobre a democracia representativa e a liberdade no mundo contemporâneo. Amicus Curiae, Criciúma, n. 3, p. 1133, 2006.

KANT, Immanuel. Crítica da razão prática. (Tradução de Valerio Rohden). 2a . ed. - São Paulo: Martins Fontes, 2008. 
KELSEN, Hans. O que é Justiça? (Tradução de Luis Carlos Borges.) 3. ed. São Paulo: Martins Fontes, 2001.

. Teoria Pura do Direito. (Tradução de João Baptista Machado.) 6. ed. São Paulo: Martins Fontes, 1998.

LASSALLE, Ferdinand. A Essência da Constituição. Rio de Janeiro: Lumen Juris, 2001.

LASWELL, Harold D. The emerging conception of the Policy Sciences. Policy Sciences, v. 1, p. 3-14, 1970.

LAFER apud GONET BRANCO, In: MENDES, G. F. (org.). Hermenêutica constitucional e direitos fundamentais. Brasília: Brasília Jurídica, 2000.

MARCONI, Marina de Andrade; LAKATOS, Eva Maria. Fundamentos de metodologia científica. 7. ed. São Paulo: Atlas, 2010.

MARQUES, Eduardo. Redes sociais e instituições na construção do Estado e da sua permeabilidade. Revista Brasileira de Ciências Sociais, v. 14, n. 41, p. 45-67, 1999.

MATTOS, Ruben Araújo de; Baptista, Tatiana Wargas de Faria. Caminhos para Análise das Políticas da Saúde. Porto Alegre: Rede Unida, 2015).

LESCURA, Caroline et al. Aspectos predominantes na Administração Pública Brasileira. http://www.emapegs.ufv.br/docs/Artigo64.pdf

MENDES, Gilmar Ferreira; COELHO, Inocêncio Mártires; BRANCO, Paulo Gustavo Gonet. Curso de direito constitucional. 3. ed. São Pau- lo: Saraiva, 2008.

MINAYO, Maria Cecília de Souza (Org.). Pesquisa social: teoria, método e criatividade. Petrópolis: Vozes, 1994.

MORAES, Alexandre de. Direito Constitucional. 19º Ed. São Paulo: Atlas, 2006.

NASCIMENTO, Milton Meira do. Rousseau: da servidão à liberdade. In Os clássicos da política, volume I (organizador Francisco C. Weffort). 14. ed. São Paulo: Ática, 2009.

ORLEANS. $2^{\text {a }}$ Vara da Comarca de Orleans. Mandado de Segurança n. ${ }^{\circ}$ 500144237.2020.8.24.0044. Impetrante: Jessé de Faria Lopes. Impetrado: Jorge Luiz Koch. Magistrada: Bruna Canella Becker. Orleans, 31/07/2020.

PELICIOLI, Angela Cristina. A atualidade da reflexão sobre a separação dos poderes. Revista de Informação Legislativa. Brasília, ano 43. n 169. jan./mar. 2006.

RIBEIRO, Hélcio; ROSA, Vanessa de Castro (orgs). Democracia dos Conselhos. 1. ed. Campo Grande: IBPJ, 2018. 
ROUSSEAU, Jean-Jacques. O Contrato Social: princípios do direito político. (Tradução de Antônio de Paula Danesi; revisão da tradução de Edson Darci Heldt). 4. ed. São Paulo: Martins Fontes, 2006.

ROSSEAU, Jean-Jacques. Do contrato social: princípios de direito político. São Paulo: Editora Revista dos Tribunais, 2002.

ROSSEAU, Jean-Jacques. O Contrato Social. São Paulo: Martins Fontes, 1996. p. 47.

RUA, Maria das Graças. Análise de Políticas Públicas. Disponível em: https://www.univali.br/pos/mestrado/mestrado-em-gestao-de-politicas-publicas/processoseletivo/SiteAssets/Paginas/default/RUA.pdf

SANTA CATARINA. Assembleia Legislativa. Regimento Interno. Disponível em http://www.alesc.sc.gov.br/sites/default/files/Regimento_22.01.2019.pdf. Acesso em $21 \mathrm{de}$ fev. de 2021.

SANTA CATARINA. Secretaria de Estado da Saúde. Portaria n. ${ }^{\circ}$ 256, de 21 de abril de 2020. Reconhece serviços essenciais. Florianópolis, abr. 2020.

SANTA CATARINA. Constituição do Estado de Santa Catarina. Promulgada em 05 de outubro de 1989, Disponível em http://leis.alesc.sc.gov.br/html/constituicao_estadual_1989.html. Acesso em $21 \mathrm{de}$ fev. de 2021.

SANTOS, Boaventura de Souza. Democratizar a democracia. Rio de Janeiro: Civilização Brasileira, 2002.

SARAVIA, Enrique; Ferrarezi, Elisabete. Políticas Públicas. Coletânea, v. 1. Brasília: Escola Nacional de Administração Pública, 2006.

SARLET, Ingo Wolfgang. A eficácia dos direitos fundamentais. 2. ed., Porto Alegre: Livraria do Advogado, 2001.

SECCHI, Leonardo. Políticas públicas: conceitos, esquemas de análise, casos práticos. São Paulo: Cengage Learning, 2013.

SIMON, Herbert A. Theories of bounded rationality. In: Mc Guire, C. E.; Redner, Roy (Eds.). Decision and organization. Amsterdam: North0Holland Publishing Company, 1972. p. 161 176.

SCHMIDT, João Pedro. Para estudar políticas públicas: aspectos conceituais, metodológicos e abordagens teóricas. Revista do Direito, Santa Cruz do Sul, v. 3, n. 56, jan. 2019. ISSN 1982-9957. Disponível em::https://doi.org/10.17058/rdunisc.v3i56.12688. . Acesso em:

SKINNER, Quentin. As fundações do pensamento político moderno. (tradução de Renato Janine Ribeiro). São Paulo: Companhia da Letras, 1996. 
SOUZA, Luiz Ricardo de; SECCHI, Leonardo. A Política Científica e Tecnológica de Santa Catarina: análise a partir do modelo de coalizões de defesa. Revista de Administração Pública, v. 48, n. 4, p. 939-960, 2014.

SOUZA, Celina. Modernização do Estado e construção de capacidade burocrática para a implementação de políticas federalizadas. Rev. Adm. Pública [online]. 2017, vol.51, n.1, pp.27-45. ISSN 1982-3134. https://doi.org/10.1590/0034-7612150933.

SOUZA, Celina Maria de. Coordenação, uniformidade e autonomia na formulação de políticas públicas: experiências federativas no cenário internacional e nacional. Cad. Saúde Pública [online]. 2019, vol.35, suppl.2, e00046818. Epub June 17, 2019. ISSN 16784464. Disponível em: https://doi.org/10.1590/0102-311x00046818.

STRECK, Lenio e MORAIS, José Luis Bolzan de. Ciência Política e Teoria Geral do Estado. Porto Alegre: Livraria do Advogado Editora, 2004. p. 31.

TEIXEIRA, João Paulo Allain; SPAREMBERGER, Raquel Fabiana Lopes.

Neoconstitucionalismo europeu e novo constitucionalismo latino-americano: um diálogo possível? RBSD - Revista Brasileira de Sociologia do Direito, v. 3., n. 1, p. 52-70, jan./abr. 2016.

TEIXEIRA, Ana Cláudia Chaves; SOUZA, Clóvis Henrique Leite de; LIMA, Paula Pompeu Fiuza. Arquitetura da participação no Brasil: uma leitura das representações políticas em espaços participativos nacionais. Brasília: Livraria do IPEA, 2012. Disponível em https://www.ipea.gov.br/portal/images/stories/PDFs/TDs/td_1735.pdf. Acesso em $21 \mathrm{de} \mathrm{fev.}$ de 2021.

VIANA, Ana L. Abordagens metodológicas em políticas públicas. Revista de Administração Pública. Rio de Janeiro, vol. 30, n. 2, mar/abr 1996, p. 5-43.

VIEIRA, Soraia. Partidos políticos e políticas públicas. In: DEL RÍO, A.; MARTON, S. (org.). Os desafios das políticas públicas no Brasil: um olhar interdisciplinar. Curitiba: CRV, 2016, p. 129-139.

O futuro da democracia. (Tradução de Marco Aurélio Nogueira). São

Paulo: Paz e Terra, 2000. BONAVIDES, Paulo. Ciência Política. São Paulo: Editora Malheiros. 14 ed., 2007.

VIEIRA, Reginaldo de Souza. A cidadania na República Participativa: Pressupostos para a articulação de um novo paradigma jurídico e político para os Conselhos de Saúde / Reginaldo de Souza Vieira; orientador, José Isaac Pilati - Florianópolis, SC, 2013.

WOLKMER, Antônio Carlos. VIEIRA, Reginaldo de Souza (Org.). Estado, política e direito: relações de poder e políticas públicas. Criciúma: UNESC, 2008.br. 